\title{
Treatment and outcomes of non-small-cell lung cancer patients with high comorbidity
}

This article was published in the following Dove Press journal: Cancer Management and Research

\author{
Jorge Rios' \\ Rahul Gosain' \\ Bernardo HL Goulart ${ }^{2}$ \\ Bin Huang ${ }^{3}$ \\ Margaret N Oechsli' \\ Jaclyn K McDowell ${ }^{4}$ \\ Quan Chen ${ }^{4}$ \\ Thomas Tucker ${ }^{4}$ \\ Goetz H Kloecker' \\ 'James Graham Brown Cancer Center, \\ University of Louisville, Louisville, KY, \\ ${ }^{2}$ Fred Hutchinson Cancer Research \\ Center, University of Washington, \\ Seattle, WA, ${ }^{3}$ Department of \\ Biostatistics, College of Public Health, \\ University of Kentucky, Lexington, KY, \\ ${ }^{4}$ Markey Cancer Center, University of \\ Kentucky, Lexington, KY, USA
}

Correspondence: Goetz H Kloecker James Graham Brown Cancer Center, University of Louisville, 529 South Jackson Street, Louisville, KY 40206, USA Tel +l 5025624370

Email ghkloe0I@exchange.louisville.edu
Background: The life expectancy of untreated non-small-cell lung cancer (NSCLC) is dismal, while treatment for NSCLC improves survival. The presence of comorbidities is thought to play a significant role in the decision to treat or not treat a given patient. We aim to evaluate the association of comorbidities with the survival of patients treated for NSCLC.

Methods: We performed a retrospective study of patients aged $\geq 66$ years with invasive NSCLC between the years 2007 and 2011 in the Surveillance, Epidemiology, and End Results Kentucky Cancer Registry. Comorbidity was measured using the Klabunde Comorbidity Index (KCI), and univariate and multivariate logistic regression models were used to measure association between receiving treatment and comorbidity. Kaplan-Meier plots were constructed to estimate time-to-event outcomes.

Results: A total of 4014 patients were identified; of this, $94.9 \%$ were white and $55.7 \%$ were male. The proportion of patients who did not receive any treatment was $8.7 \%, 3.9 \%, 19.1 \%$, and $23.5 \%$ for stages I, II, III, and IV, respectively ( $p<0.0001)$. In multivariate analysis, older age, higher stage, and higher comorbidity $(\mathrm{KCI} \geq 3)$ were associated with a lower likelihood of receiving any treatment. The median overall survival (OS) for untreated and $\mathrm{KCI}=0$ was 17.7 months for stages I and II, 2.3 months for stage III, and 1.3 months for stage IV. The median OS for treated and $\mathrm{KCI}=0$ was 58.9 months for stages I and II, 16.8 months for stage III, and 5.8 months for stage IV $(p<0.01)$. Treatment was an independent predictor of OS in multivariate analysis that included KCI scores.

Conclusion: Our data suggest that lung cancer patients may derive a survival benefit from therapies, regardless of the presence of comorbidities, although the degree of benefit seems to decrease with higher KCI scores.

Keywords: non-small-cell lung cancer, Klabunde, cancer, comorbidity index, lung cancer

\section{Introduction}

Non-small-cell lung cancer (NSCLC), when untreated, proves invariably deadly in the vast majority of patients within 1 year. ${ }^{1}$ NSCLC is diagnosed at advanced stages (III or IV) in $70 \%$ of the cases in the USA, and $19 \%-24 \%$ of the individuals with advanced NSCLC are never treated. ${ }^{2,3}$ Furthermore, untreated NSCLC accounts for $55 \%$ of all untreated advanced cancers in the USA. ${ }^{3}$ There are multiple reasons why patients do not receive therapy; however, comorbidity consistently stands out as a reported predictor for lack of therapy for NSCLC patients. ${ }^{4-6}$ Comorbidity burden has been described to be higher along with the high prevalence of smoking in lung cancer compared with other types of solid tumors. ${ }^{7}$ The presence of comorbidities can influence treatment selection due to organ damage or increased risk of adverse 
effects. Currently, it remains unclear if the comorbidity burden alone is predictive of outcome in a lung cancer patient or only when it affects patient's performance status. ${ }^{5}$ Similarly, there are limited data regarding the actual benefit of treating lung cancer in patients with a high comorbidity burden. In this study, we aim to evaluate the association of comorbidities with the treatment and the survival of NSCLC patient population along with the degree of benefit from treatment in those patients with comorbidities.

\section{Methods}

\section{Patient population and eligibility criteria}

A retrospective cohort study of patients aged $\geq 66$ years diagnosed with invasive NSCLC stages I through IV between the years 2007 and 2011 in the state of Kentucky, was performed using data from the Surveillance, Epidemiology, and End Results (SEER) registry linked to claim files from the US Medicare database (SEER-Medicare). Medicare provides insurance to elderly Americans and this study included patients who had continuous Medicare part A (hospital insurance) and part B (medical insurance) coverage 12 months prior and 6 months after lung cancer diagnosis or death, whichever came first. We excluded patients with health maintenance organization coverage in the previous 12 months, those with Medicare eligibility due to end-stage renal disease or disability, and those with a concurrent diagnosis of cancer within 3 months of lung cancer diagnosis (Figure 1). The chair granted an Institutional Review Board approval after an expedited review application at the University of Louisville, Kentucky.

\section{Cancer treatment}

Treatment information was obtained from both registry and claims data. Surgical treatment data were obtained using the
SEER Kentucky Cancer Registry (KCR) surgery codes and claims data from the SEER Medicare Provider Analysis and Review (MEDPAR) and Carrier Claims - National Claims History (NCH) files. Radiation treatment and chemotherapy data were obtained using KCR treatment codes, MEDPAR, $\mathrm{NCH}$, and the SEER outpatient claim files. Furthermore, the SEER Durable Medical Equipment and Prescription Drug Event files were evaluated to determine the use of chemotherapy. A full description of the specific codes used can be found in Tables S1 and S2.

\section{Variables of interest}

Age at the time of diagnosis, race/ethnic information and the stage at diagnosis were obtained from KCR. Race/ ethnicity was categorized into 3 groups: White, black, and other. Comorbidity burden on diagnosis was measured using the lung cancer-specific Klabunde Comorbidity Index (KCI). ${ }^{8}$ The KCI, a continuous comorbidity index based on the comorbid conditions identified by Charlson index that incorporates the diagnostic and procedure data from physician claims, was converted into a categorical variable of increasing severity of comorbidity: no and very low comorbidity $(\mathrm{KCI}=0)$, low comorbidity $(\mathrm{KCI}=1)$, moderate comorbidity $(\mathrm{KCI}=2)$, and high comorbidity $(\mathrm{KCI} \geq 3){ }^{8}$ Poverty at the residential census tract level was categorized in 4 groups according to the percentage of residents with an income below the US federal poverty line $(<8 \%, 8 \%-15 \%$, $15 \%-30 \%$, or $>30 \%$ ). Education at the residential census tract level was categorized into 4 groups based on the proportion of adult residents ( $\geq 25$ years old) with less than high school education $(<15 \%, 15 \%-25 \%, 35 \%-35 \%$, and $>35 \%$ ). Geographic origin of the patient was classified into metropolitan versus rural origin and Appalachian versus

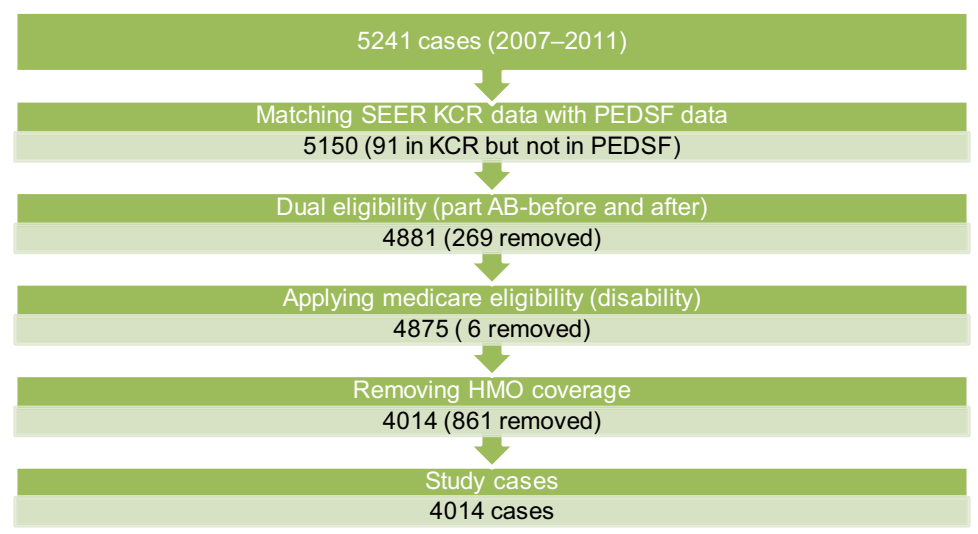

Figure I Flow diagram - patient population.

Abbreviations: HMO, health maintenance organization; KCR, Kentucky Cancer Registry; PEDSF, patient entitlement and diagnosis summary file; SEER, Surveillance, Epidemiology, and End Results. 
non-Appalachian origin according to the US Census Bureau definitions.

Outcome variables included treatment status and overall survival (OS) from the time of diagnosis. The treatment status was a dichotomous variable, defined as any treatment (including surgery, radiation, chemotherapy, or a combination of those) versus no treatment. OS was measured from the day of diagnosis to the date of death or the date of last contact.

\section{Statistical analysis}

Descriptive analysis and $\chi^{2}$ tests were used to assess the association between treatment status and covariates. Multivariate logistic regression models were used to explore the association between receiving treatment and comorbidity, while accounting for the potential confounding effect of other covariates. The interaction effects and the goodness of fit were examined. The final model only included the significant covariates. Kaplan-Meier estimates and log-rank tests were calculated to examine the survival curves of various treatment and comorbidity combinations. Cox regression survival models were fitted to identify the significant factors associated with survival while controlling for other covariates. All tests were 2-sided with a 0.05 significance level. SAS 9.3 was used for all analysis.

\section{Results}

We identified 4014 cases of invasive NSCLC as eligible for analysis. Most patients (94.9\%) were Caucasian, and 55.7\% were male. Approximately half of the patients lived in rural areas $(48 \%)$ ). KCI scores were 0 (no or very low comorbidity), 1 (low comorbidity), 2 (moderate comorbidity), and $\geq 3$ (severe comorbidity) in $46.8 \%, 29.1 \%, 10.8 \%$, and $13.3 \%$ of the study sample, respectively.

\section{Receiving lung cancer treatment}

The proportion of patients by stage who did not receive any treatment for lung cancer were $8.7 \%, 3.9 \%$, and $19.1 \%$ for stage I, stage II, and stage III, respectively $(p<0.0001)$. A total of $49.1 \%$ of stage IV patients did not receive any chemotherapy and $23.5 \%$ of this cohort did not receive any treatment modality $(p<0.0001)$. Compared with the treated individuals, the untreated population had a higher proportion of patients $>75$ years old, diagnosed at stage IV, residing in rural areas, having higher comorbidity index scores, and more likely to live in areas of lower education levels. Of the patients with a $\mathrm{KCI} \geq 3 \%, 25.4 \%$ were untreated, compared with $16.4 \%$ of patients with $\mathrm{KCI}=0 \%, 15.7 \%$ with $\mathrm{KCI}=1 \%$, and $18.2 \%$ with $\mathrm{KCI}=2(p<0.0001)$ (Table 1$)$. Across all stages, the proportion of patients with high comorbidity (KCI $\geq 3$ ) was similarly distributed $(15.2 \%$ in stages I-II, $12.9 \%$ in stage III, and $12 \%$ in stage IV). In multivariate analysis, older age, more advanced stage, higher comorbidity index, and residency in rural areas were significantly associated with a lower likelihood of receiving lung cancer treatment.

\section{Survival analysis}

In patients with $\mathrm{KCI}=0$, the median $\mathrm{OS}$ for the untreated group was 17.7 months for stages I and II, 2.3 months for stage III, and 1.3 months for stage IV. For $\mathrm{KCI}=0$ patients who received treatment, the median OS was 58.9, 16.8, and 5.8 months for stages I and II, III, and IV, respectively (Figures 2-4). In patients with $\mathrm{KCI} \geq 3$, the median $\mathrm{OS}$ for the untreated group was $6.1,1.6$, and 1.2 months for stages I and II, III, and IV, respectively. For the KCI $\geq 3$ patients who received any treatment, the median OS was 22.9, 10.9, and 3.7 months for stages I and II, III, and IV, respectively (Figures 2-4). In multivariate Cox regression models, age, gender, stage, KCI scores, and receiving treatment were associated with survival (Table 2). In particular, higher comorbidity was independently associated with lower OS $(\mathrm{HR}=1.51$ for $\mathrm{KCI} \geq 3$ vs $\mathrm{KCI}=0$; 95\% CI 1.363-1.679; $p<0.001)$.

Within each comorbidity index level, patients who received no therapy had worse survival than those who received any therapy (Table 3 ).

\section{Discussion}

Our study confirms the previously reported association between the presence of comorbidities and lower likelihood of receiving cancer treatment. ${ }^{4-6}$ However, conflicting data were found with regard to the association between comorbidities and on survival of lung cancer patients. Luchtenborg et $\mathrm{al}^{9}$ found that severe comorbidity had a large detrimental impact on the survival of lung cancer patients who undergo curative lung resection. In contrast, a retrospective cohort study from the Netherlands showed that the negative effect of comorbidity on survival in nonsurgical candidates was present only in patients treated with chemotherapy. ${ }^{10}$ In an analysis of all cancer cases diagnosed between 1992 and 2005 included in the US SEER database, Edwards et $\mathrm{al}^{7}$ found that the influence of comorbidities on the probability of both cancer-specific and non-cancer-related mortality was smaller for lung cancer compared with other cancers. Our study adds to the body of evidence suggesting that comorbidities influence physicians' decision to recommend treatment for NSCLC, and that comorbidity levels may correlate with 
Table I Characteristics of patients by treatment status

\begin{tabular}{|c|c|c|c|c|c|c|c|}
\hline \multirow[t]{2}{*}{ Variable } & \multicolumn{2}{|l|}{ Total } & \multicolumn{2}{|c|}{ No treatment } & \multicolumn{2}{|c|}{ Received treatment } & \multirow[t]{2}{*}{$p$-value } \\
\hline & $\mathbf{N}$ & $\%$ & $\mathbf{N}$ & $\%$ & $\mathbf{N}$ & $\%$ & \\
\hline Age group (years) & & & & & & & $<0.001$ \\
\hline $66-70$ & $|24|$ & 30.9 & 144 & 11.6 & 1097 & 88.4 & \\
\hline $7 I-75$ & $|15|$ & 28.7 & 181 & 15.7 & 970 & 84.3 & \\
\hline $76-80$ & 907 & 22.6 & 170 & 18.7 & 737 & 81.3 & \\
\hline $81-85$ & 525 & 13.1 & 144 & 27.4 & 381 & 72.6 & \\
\hline $86+$ & 190 & 4.7 & 67 & 35.3 & 123 & 64.7 & \\
\hline Grade & & & & & & & $<0.001$ \\
\hline Well-differentiated & 198 & 4.9 & 23 & 11.6 & 175 & 88.4 & \\
\hline Moderately differentiated & 981 & 24.4 & 103 & 10.5 & 878 & 89.5 & \\
\hline Poorly differentiated & $|14|$ & 28.4 & 152 & 13.3 & 989 & 86.7 & \\
\hline Undifferentiated & 56 & 1.4 & 6 & 10.7 & 50 & 89.3 & \\
\hline Unknown & 1638 & 40.8 & 422 & 25.8 & 1216 & 74.2 & \\
\hline Race & & & & & & & 0.112 \\
\hline White & 3809 & 94.9 & 665 & 17.5 & 3144 & 82.5 & \\
\hline Black & 193 & 4.8 & $4 I$ & 21.2 & 152 & 78.8 & \\
\hline Other & 12 & 0.3 & 0 & 0.0 & 12 & 100.0 & \\
\hline Sex & & & & & & & 0.745 \\
\hline Male & 2235 & 55.7 & 397 & 17.8 & 1838 & 82.2 & \\
\hline Female & 1779 & 44.3 & 309 & 17.4 & 1470 & 82.6 & \\
\hline Histology type & & & & & & & 0.049 \\
\hline Adenocarcinoma & 1862 & 46.4 & 331 & 17.8 & $|53|$ & 82.2 & \\
\hline Squamous & 1907 & 47.5 & 346 & 18.1 & $|56|$ & 81.9 & \\
\hline Other & 245 & 6.1 & 29 & 11.8 & 216 & 88.2 & \\
\hline Metro & & & & & & & 0.002 \\
\hline Non-metro & 1927 & 48.0 & 376 & 19.5 & $|55|$ & 80.5 & \\
\hline Metro & 2087 & 52.0 & 330 & 15.8 & 1757 & 84.2 & \\
\hline Appal & & & & & & & 0.016 \\
\hline Non-Appalachian & 2840 & 70.8 & 473 & 16.7 & 2367 & 83.3 & \\
\hline Appalachian & 1174 & 29.2 & 233 & 19.8 & 941 & 80.2 & \\
\hline Poverty & & & & & & & 0.107 \\
\hline Low poverty $(0 \%-7.9 \%)$ & 899 & 22.4 & 135 & 15.0 & 764 & 85.0 & \\
\hline Below US average $(8 \%-14.9 \%)$ & 1228 & 30.6 & 230 & 18.7 & 998 & 81.3 & \\
\hline Above US average(I5\%-29.9\%) & 1425 & 35.5 & 263 & 18.5 & 1162 & 81.5 & \\
\hline High poverty $(30+\%)$ & 462 & 11.5 & 78 & 16.9 & 384 & 83.1 & \\
\hline High school education & & & & & & & 0.004 \\
\hline High level education (85+ \%) & 698 & 17.4 & 95 & 13.6 & 603 & 86.4 & \\
\hline About US average (75\%-84.9\%) & 956 & 23.8 & 172 & 18.0 & 784 & 82.0 & \\
\hline Low level education (65\%-74.9\%) & 1640 & 40.9 & 322 & 19.6 & 1318 & 80.4 & \\
\hline Very low education $(<65 \%)$ & 720 & 17.9 & 117 & 16.3 & 603 & 83.8 & \\
\hline \multicolumn{3}{|c|}{ Lung cancer Klabunde comorbidity index } & & & & & 0.001 \\
\hline No or very low comorbidity & $150 \mid$ & 37.4 & 258 & 17.2 & 1243 & 82.8 & \\
\hline 1 & 1259 & 31.4 & 192 & 15.3 & 1067 & 84.7 & \\
\hline 2 & 644 & 16.0 & 116 & 18.0 & 528 & 82.0 & \\
\hline $3+$ & 610 & 15.2 & 140 & 23.0 & 470 & 77.0 & \\
\hline
\end{tabular}

other clinical factors influencing treatment choices, such as performance status.

Despite the role of comorbidity assessments in the choice of treatments, limited data are available about the actual benefit of lung cancer therapy in patients with high comorbidity burden. Patients who are more sick are more likely to be excluded from standard clinical trials, leaving clinicians with little objective assessments of treatment benefits in the setting of high comorbidities. Furthermore, when considering the toxicity profile of chemotherapy, the intensity of treatment is limited by organ function, which can be directly impacted by the presence of comorbidities. Patients with higher burden of comorbidities, as determined by KCI score of 3 or higher, constituted $\sim 15 \%$ of our study population. In this group, we 
Product-limit survival estimates

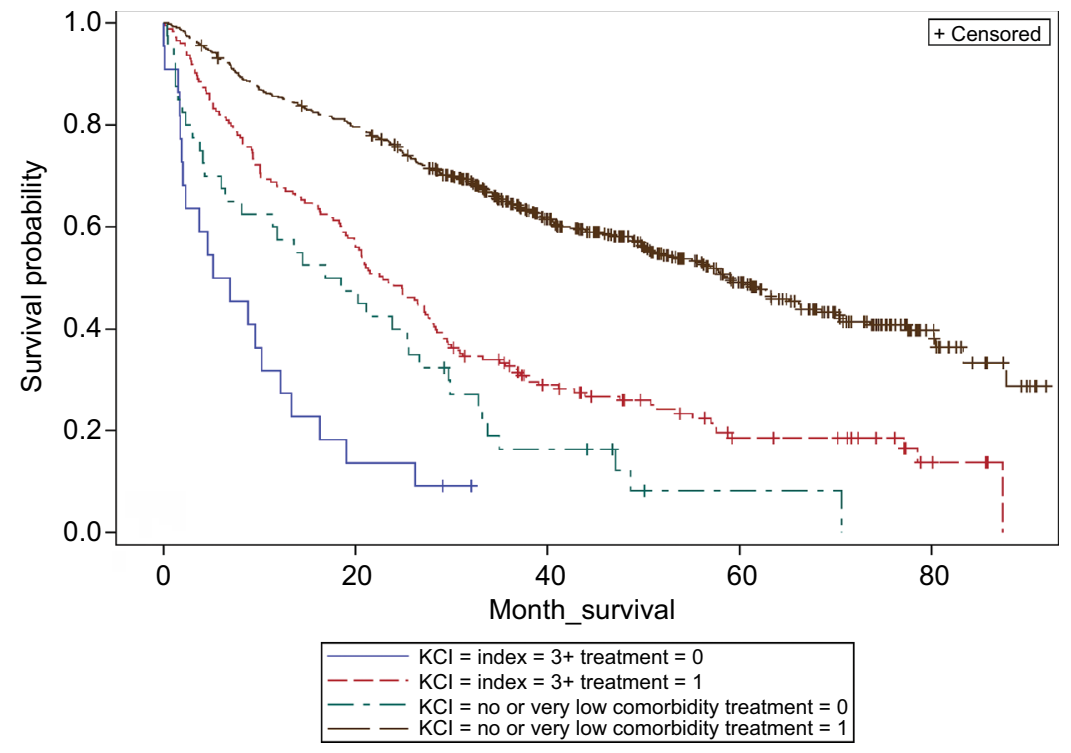

Figure 2 Survival estimates by comorbidity level and treatment status in stage I and II patients.

Abbreviation: $\mathrm{KCl}$, Klabunde Comorbidity Index.

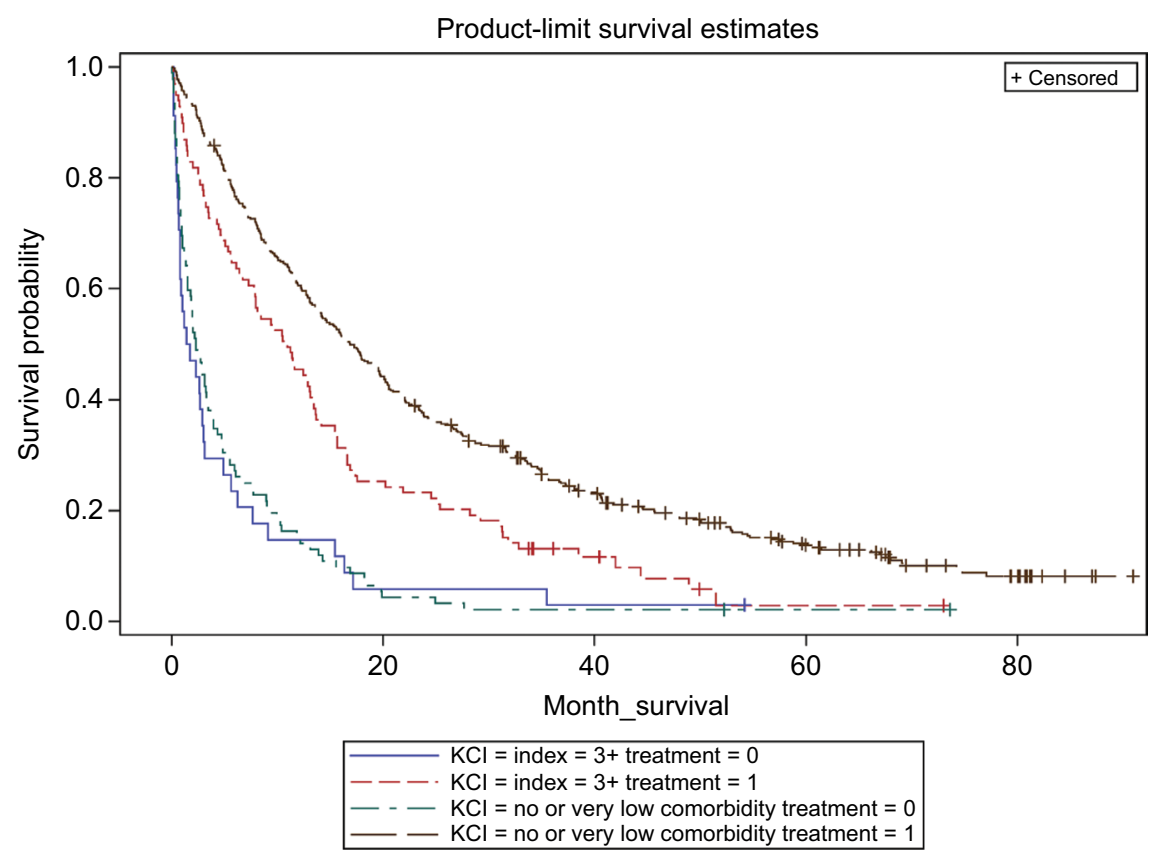

Figure 3 Survival estimates by comorbidity level and treatment status in stage III patients.

Abbreviation: $\mathrm{KCl}$, Klabunde Comorbidity Index.

observed significantly higher survival among those individuals who received any cancer-specific therapy compared with their equally comorbid counterparts who did not. Although selection bias could have resulted in overestimated measures of treatment effects in this observational study, our data indicate that patients may still derive a survival benefit from cancer treatments in the presence of high comorbidity. Likewise, we recognize that comorbidity is not a sole factor used to decide against treatment in NSCLC patients.

Not all comorbid conditions are expected to have an equal impact on the treatment. The most common comorbidities in lung cancer patients are chronic obstructive pulmonary 


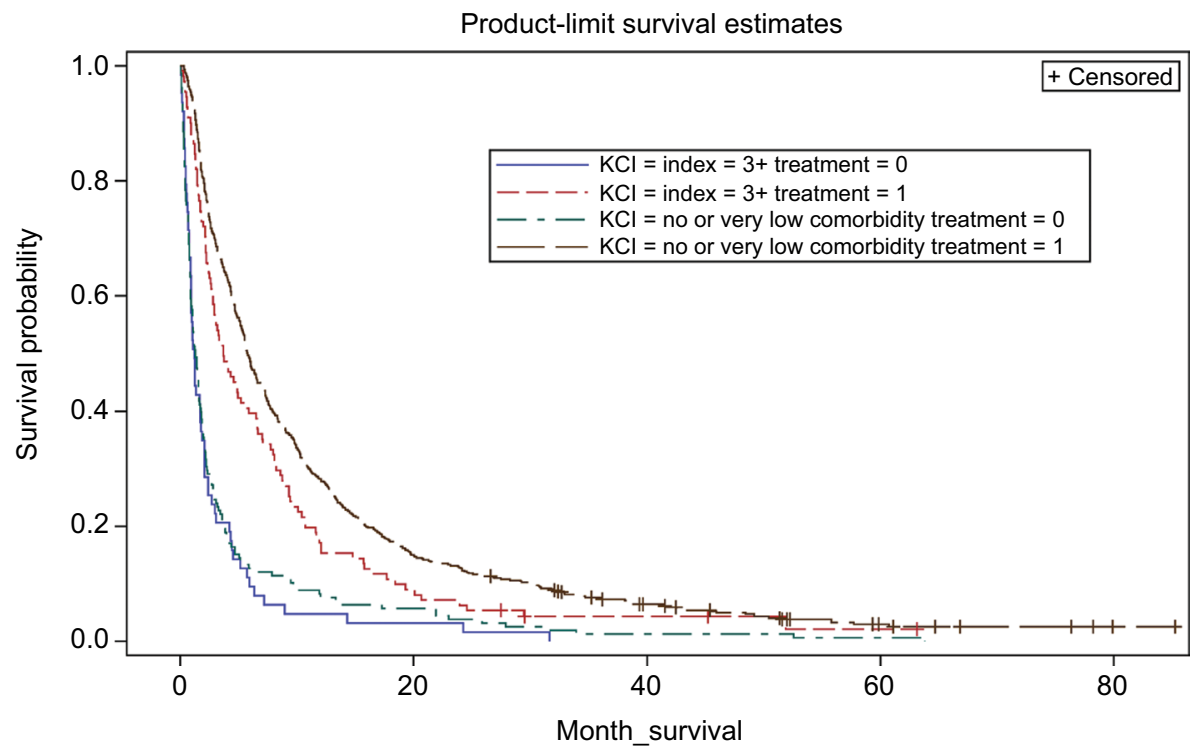

Figure 4 Survival estimates by comorbidity level and treatment status in stage IV patients. Abbreviation: $\mathrm{KCl}$, Klabunde Comorbidity Index.

Table 2 Multivariate analysis of factors associated with receiving treatment

\begin{tabular}{|c|c|c|c|c|}
\hline Variable & OR & $95 \% \mathrm{Cl}$ & & $p$-value \\
\hline & & & & $<0.001$ \\
\hline Male & 1.176 & 1.096 & 1.261 & \\
\hline Female & Ref & & & \\
\hline Age group (years) & & & & $<0.001$ \\
\hline $7 \mathrm{I}-75$ & 1.025 & 0.936 & 1.123 & \\
\hline $76-80$ & 1.284 & 1.167 & 1.413 & \\
\hline $81-85$ & 1.435 & 1.280 & 1.607 & \\
\hline $86+$ & 1.399 & 1.186 & 1.651 & \\
\hline $66-70$ & Ref & & & \\
\hline AJCC stage & & & & $<0.001$ \\
\hline II & 1.493 & 1.257 & $\mathrm{I} .774$ & \\
\hline III & 2.413 & 2.177 & 2.673 & \\
\hline IV & 4.298 & 3.887 & 4.752 & \\
\hline Unknown & 2.365 & 1.972 & 2.838 & \\
\hline I & Ref & & & \\
\hline Grade & & & & $<0.001$ \\
\hline Moderately differentiated & 1.287 & 1.063 & 1.556 & \\
\hline Poorly differentiated & 1.463 & 1.212 & 1.767 & \\
\hline Undifferentiated & 1.705 & 1.202 & 2.418 & \\
\hline Unknown & 1.776 & 1.478 & 2.134 & \\
\hline Well-differentiated & Ref & & & \\
\hline Comorbidity index & & & & $<0.001$ \\
\hline 1 & 1.122 & 1.033 & 1.218 & \\
\hline 2 & 1.238 & 1.104 & 1.389 & \\
\hline 3 & 1.513 & 1.363 & 1.679 & \\
\hline No or very low comorbidity & Ref & & & \\
\hline Treatment status & & & & $<0.001$ \\
\hline No & 2.474 & 2.259 & 2.708 & \\
\hline Yes & Ref & & & \\
\hline Histology type & & & & 0.007 \\
\hline Squamous & 1.031 & 0.958 & 1.109 & \\
\hline Other & 1.285 & 1.100 & 1.502 & \\
\hline Adenocarcinoma & Ref & & & \\
\hline
\end{tabular}

Abbreviation: AJCC, American Joint Committee on Cancer.
Table 3 OS HR untreated vs. treated in each $\mathrm{KCl}$ category

\begin{tabular}{lllll}
\hline & $\mathbf{K C l ~ 0}$ & $\mathbf{K C l ~ I}$ & $\mathbf{K C l} \mathbf{2}$ & $\mathrm{KCl} \geq \mathbf{3}$ \\
\hline OS (HR) & $\mathrm{HR} \mathrm{3.47}$ & $\mathrm{HR} \mathrm{3.05}$ & $\mathrm{HR} \mathrm{3.05}$ & $\mathrm{HR} 3.12$ \\
Untreated & $\mathrm{P}<0.00 \mathrm{I}$, & $\mathrm{P}<0.00 \mathrm{I}$, & $\mathrm{P}<0.00 \mathrm{I}$ & $\mathrm{P}<0.00 \mathrm{I}$ \\
vs & $95 \% \mathrm{Cl}$ & $95 \% \mathrm{Cl}$ & $95 \% \mathrm{Cl}$ & $95 \% \mathrm{Cl}$ \\
treated & $(3.0-3.9)$ & $(2.5-3.6)$ & $2.5-3.6$ & $(2.5-3.8)$ \\
\hline
\end{tabular}

disease, coronary artery disease, congestive heart failure, diabetes, and renal insufficiency. ${ }^{46}$ Cardiac comorbidity and chronic obstructive pulmonary disease have been described as independent risk factors affecting the development of toxicity and the effectiveness of cancer therapy. ${ }^{11-13}$ In contrast, no clear role has been described for other comorbidities (such as liver disease or Alzheimer's dementia) that are also included in the construction of the KCI. Moving forward, it is important for health care providers and patients to realize that, with newer therapeutic options such as immunotherapy, organ dysfunction and the comorbidity burden should play a lesser role in the decision to treat lung cancer.

There are several limitations to our analysis. The data set is from 2007 to 2011 and may not reflect more current practice patterns. This is particularly important since the recent development of immunotherapy, which is believed to have a more favorable safety profile and might not be affected by comorbidities compared with the safety profile of cytotoxic chemotherapy. Given that the study population is restricted to Kentucky residents, the results may not be generalizable to the US NSCLC population. ${ }^{14-19}$ The SEER-Medicare database does not provide data on other clinically relevant prognostic 
factors, including performance status and weight loss, or nonclinical factors, such as access to care and social support. The lack of ability to account for the potential confounding effect of these factors could have biased our results.

\section{Conclusion}

NSCLC patients with higher comorbidity burden are less likely to receive cancer-specific treatment and more likely to die. However, it appears that even in individuals with high comorbidity burden, cancer-specific treatments seem to improve survival, independently of their stage at presentation. The treatment benefit observed in the high comorbid population is likely a result of multiple factors, including the treatment itself. The impact of comorbidity along with performance status, medical and social support system, and the presenting stage play an important role in decision to treat lung cancer.

\section{Acknowledgment}

This study was supported by Kentucky Lung Cancer Education and Survivorship Grant (LEADS).

\section{Disclosure}

The authors report no conflicts of interest in this work.

\section{References}

1. Raz DJ, Zell JA, Ou SH, Gandara DR, Anton-Culver H, Jablons DM. Natural history of stage I non-small cell lung cancer: implications for early detection. Chest. 2007;132(1):193-199.

2. Goulart BH, Reyes CM, Fedorenko CR, et al. Referral and treatment patterns among patients with stages III and IV non-small-cell lung cancer. J Oncol Pract. 2013;9(1):42-50.

3. Small AC, Tsao CK, Moshier EL, et al. Prevalence and characteristics of patients with metastatic cancer who receive no anticancer therapy. Cancer. 2012;118(23):5947-5954.

4. Islam KM, Jiang X, Anggondowati T, Lin G, Ganti AK. Comorbidity and survival in lung cancer patients. Cancer Epidemiol Biomarkers Prev. 2015;24(7):1079-1085.

5. Tammemagi CM, Nesulund-Dudas C, Simoff M, Kvale P. Impact of comorbidity on lung cancer survival. Int J Cancer. 2003;103(6):792-802.

6. Grose D, Devereux G, Milroy R. Comorbidity in lung cancer: important but neglected. a review of the current literature. Clin Lung Cancer. 2011;12(4):207-211.
7. Edwards BK, Noone AM, Mariotto AB, et al. Annual report to the nation on the status of cancer, 1975-2010, featuring prevalence of comorbidity and impact on survival among persons with lung, colorectal, breast, or prostate cancer. Cancer. 2014;120(9):1290-1314.

8. Klabunde CN, Potosky AL, Legler JM, Warren JL. Development of a comorbidity index using physician claims data. J Clin Epidemiol. 2000;53(12): $1258-1267$.

9. Luchtenborg M, Jakobsen E, Krasnik M, Linklater KM, Mellemgaard A, Møller H. The effect of comorbidity on stage-specific survival in resected non-small cell lung cancer patients. Eur J Cancer. 2012;48(18):3386-3395.

10. Mellemgaard A, Luchtenborg M, Iachina M, et al. Role of comorbidity on survival after radiotherapy and chemotherapy for nonsurgically treated lung cancer. J Thorac Oncol. 2015;10(2):272-279.

11. Nalbantov G, Kietselaer B, Vandecasteele K, et al. Cardiac comorbidity is an independent risk factor for radiation-induced lung toxicity in lung cancer patients. Radiother Oncol. 2013;109(1):100-106.

12. Zhai R, Yu X, Shafer A, Wain JC, Christiani DC. The impact of coexisting COPD on survival of patients with early-stage non-small cell lung cancer undergoing surgical resection. Chest. 2014;145(2):346-353.

13. Lee SJ, Lee J, Park YS, et al. Impact of chronic obstructive pulmonary disease on the mortality of patients with non-small-cell lung cancer. J Thorac Oncol. 2014;9(6):812-817.

14. Gadgeel SM, Kalemkerian GP. Racial differences in lung cancer. Cancer Metastasis Rev. 2003;22(1):39-46.

15. Patel JD, Socinski MA, Garon EB et al. PointBreak: a randomized phase III study of pemetrexed plus carboplatin and bevacizumab followed by maintenance pemetrexed and bevacizumab versus paclitaxel plus carboplatin and bevacizumab followed by maintenance bevacizumab in patients with stage IIIB or IV nonsquamous non-small-cell lung cancer. J Clin Oncol. 2013;31(34):4349-4357.

16. Barlesi F, Scherpereel A, Gorbunova V, et al. Maintenance bevacizumabpemetrexed after first-line cisplatin-pemetrexed-bevacizumab for advanced nonsquamous nonsmall-cell lung cancer: updated survival analysis of the AVAPERL (MO22089) randomized phase III trial. Ann Oncol. 2014;25(5):1044-1052.

17. Scagliotti GV, Parikh P, von Pawel J, et al. Phase III study comparing cisplatin plus gemcitabine with cisplatin plus pemetrexed in chemotherapy-naive patients with advanced-stage non-small-cell lung cancer. J Clin Oncol. 2008;26(21):3543-3451.

18. Zhou C, Wu YL, Chen G, et al. Final overall survival results from a randomised, phase III study of erlotinib versus chemotherapy as firstline treatment of EGFR mutation-positive advanced non-small-cell lung cancer (OPTIMAL, CTONG-0802). Ann Oncol. 2015;26(9): 1877-1883.

19. Rosell R, Carcereny E, Gervais R, et al; Spanish Lung Cancer Group in collaboration with Groupe Français de Pneumo-Cancérologie and Associazione Italiana Oncologia Toracica. Erlotinib versus standard chemotherapy as first-line treatment for European patients with advanced EGFR mutation-positive non-small-cell lung cancer (EURTAC): a multicentre, open-label, randomised phase 3 trial. Lancet Oncol. 2012;13(3): 239-246. 


\section{Supplementary materials}

Table SI Identification of claims for radiotherapy (the following table shows the code values that were used for searching lung cancer radiotherapy under different types of radiotherapy codes)

\begin{tabular}{ll}
\hline Medicare file name & Type of code \\
\hline MedPAR & Diagnosis codes only \\
& Procedure codes only \\
NCH & Diagnosis codes only \\
& CPT and HCPCS codes \\
Outpatient & Diagnosis codes only \\
& CPT and HCPCS codes \\
& Revenue center \\
\hline Type of radiotherapy code & Code values \\
\hline ICD-9 diagnosis codes & V580, V66I,V67I \\
ICD-9 procedure codes & $922 I-9229$ \\
HCPCS codes & $7726 I-77299,77300-77399,7740 I-77499,77520,77523,76370,76950,77750-77799, C I 325$, \\
& $C I 348, C$ CI350, CI700-CI7I2, CI7I5-CI720, CI728, CI790-CI806, C26I6, C2632, C2633, \\
& C97I4, C97I5, \\
Revenue code & G0I74, G0I78, G0I79, G026I, G0256, G0273, G0274, G0338-G0340 \\
\hline
\end{tabular}

Abbreviations: CPT, Current Procedure Terminology; HCPCS, Healthcare Common Procedure Coding System; ICD, International Classification of Diseases; MedPAR, Medicare Provider Analysis and Review; NCH, National Claims History.

Table S2 Identification of claims for chemotherapy (the following tables show the code values that were used for searching lung cancer chemotherapy)

\begin{tabular}{|c|c|}
\hline Medicare file name & Type of code \\
\hline \multirow[t]{2}{*}{ MedPAR } & Diagnosis codes only \\
\hline & Procedure codes only \\
\hline \multirow[t]{2}{*}{$\mathrm{NCH}$} & Diagnosis codes only \\
\hline & CPT and HCPCS codes \\
\hline \multirow[t]{2}{*}{ Outpatient } & Diagnosis codes only \\
\hline & CPT and HCPCS codes \\
\hline \multirow[t]{3}{*}{ DME } & Diagnosis codes only \\
\hline & CPT and HCPCS codes \\
\hline & National Drug Code \\
\hline Type of chemotherapy code & Code values \\
\hline ICD-9 diagnosis codes & V662, V58I, V58II, V5812 \\
\hline ICD-9 procedure codes & $0010,1770,9925,9928$ \\
\hline \multirow[t]{16}{*}{ HCPCS codes } & $51720,96400,5 I 720,96400,9640 \mathrm{I}, 96402,96405,96406,96408,96409,964 I 0,964 I I, 964 I 2$, \\
\hline & $96413,96414,96415,96416,96417,96420,96422,96423,96425,96440,96445,96446,96450$, \\
\hline & $96520,9652 \mathrm{I}, 96522,96523,96530,96542,96545,96549,36823,61517,95990,9599 \mathrm{I}, 05 \mathrm{I} 9 \mathrm{~F}$ \\
\hline & C8953, C8954, C8955, G0355, G0357, G0358, G0359, G0360, G036I, G0362, G0370, J7150, \\
\hline & Q0083, Q0084, Q0085, S5019, S5020, S9329, S9330, S9331, S9425, Cl086, CII66, CII67, \\
\hline & Cl178, C9012, C9110, C9127, C9205, C9213, C9214, C9215, C9217, C9218, C9235, C9257, \\
\hline & C9262, C9414, C9415, C9417, C9418, C9419, C9420, C9421, C9422, C9423, C9424, C9425, \\
\hline & C9426, C9427, C9429, C943I, C9432, C9433, C9437, C9440, J0594, J0894, J85I0, J8520, \\
\hline & J852I, J8530, J8560, J8565, J8600, J86I0, J8700, J8705, J8999, J9000, J900I, J9010, J90I7, J9020, \\
\hline & J9025, J9027, J9033, J9035, J9040, J904I, J9045, J9050, J9055, J9060, J9062, J9065, J9070, J9080, \\
\hline & J9090, J909।, J9092, J9093, J9094, J9095, J9096, J9097, J9098, J9100, J91 10, J9120, J9130, J9140, \\
\hline & J9150, J915।, J9170, J917।, J9178, J9180, J9181, J9182, J9185, J9190, J9200, J920।, J9206, J9207, \\
\hline & J9208, J92II, J9230, J9245, J9250, J9260, J926I, J9263, J9264, J9265, J9266, J9268, J9270, J9280, \\
\hline & J9290, J929I, J9293, J9300, J9303, J9305, J9307, J93 I0, J93I5, J9320, J9328, J9330, J9340, J9350, \\
\hline & J935I, J9355, J9357, J9360, J9370, J9375, J9380, J9390, J9999, Q2017, Q2024, S0087, S0088, \\
\hline & SOII5, SOII6, S0I72, S0176, S0I78, S0I82 \\
\hline
\end{tabular}


Table S2 (Continued)

\begin{tabular}{|c|c|}
\hline Type of chemotherapy code & Code values \\
\hline NDC codes & 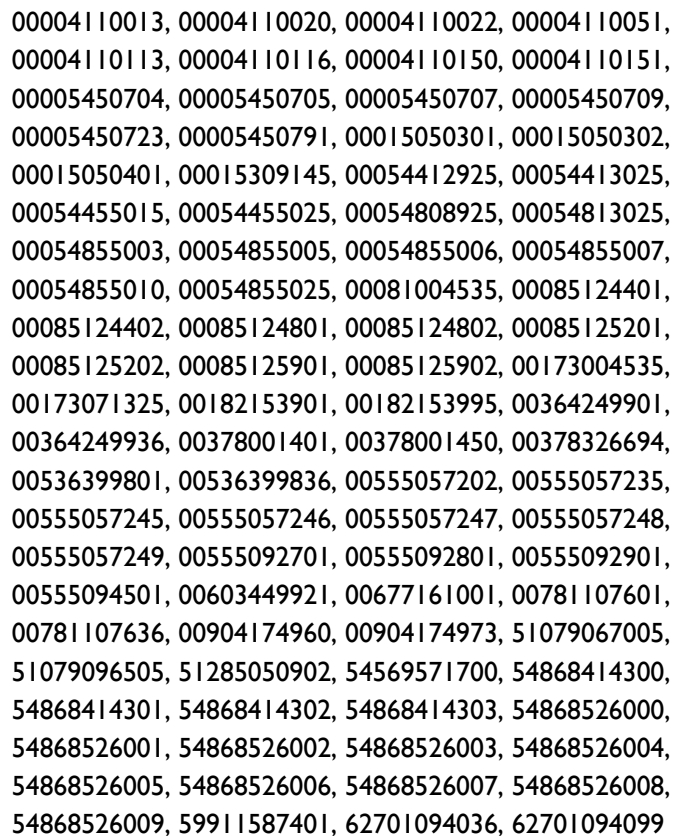 \\
\hline
\end{tabular}

Abbreviations: CPT, Current Procedure Terminology; DME, durable medical equipment; HCPCS, Healthcare Common Procedure Coding System; ICD, International Classification of Diseases; MedPAR, Medicare Provider Analysis and Review; NCH, National Claims History; NDC, National Drug Code.

Cancer Management and Research

\section{Publish your work in this journal}

Cancer Management and Research is an international, peer-reviewed open access journal focusing on cancer research and the optimal use of preventative and integrated treatment interventions to achieve improved outcomes, enhanced survival and quality of life for the cancer patient. The manuscript management system is completely online and includes
Dovepress

a very quick and fair peer-review system, which is all easy to use. Visit http://www.dovepress.com/testimonials.php to read real quotes from published authors.

Submit your manuscript here: https://www.dovepress.com/cancer-management-and-research-journal 